\title{
Studies on Transplantation of Marine Turtle Nests at Karachi Coast (Sindh), Pakistan
}

\author{
Fehmida Firdous ${ }^{\mathrm{a}}$, Sohail Barkati ${ }^{\mathrm{b} *}$ and Solaha Rahman ${ }^{\mathrm{b}}$ \\ ${ }^{a}$ Sindh Wildlife Department, Karachi, Pakistan \\ ${ }^{b}$ Department of Zoology, University of Karachi, Karachi-75270, Pakistan
}

(received April 29, 2010; revised August 2, 2010; accepted September 16, 2010)

\begin{abstract}
Egg clutches of two species of marine turtles, namely Chelonia mydas and Lepidochelys olivacea, were collected during 1974 to 1997 and transplanted to the protected enclosures. The emerging hatchlings were released to the natural environment. The experiment helped to produce an average of 19495.5 hatchlings per year of green and 1174.5 per year of olive ridley turtles.
\end{abstract}

Keywords: transplantation, turtles, Chelonia mydas, Lepidochelys olivacea, green turtles

\section{Introduction}

Overexploitation including indiscriminate slaughtering and destruction of nesting sites are considered main reasons of inclusion of the marine turtles of Pakistan in the list of threatened species in Red Data Book of IUCN (Groombridge, 1982). Intensive programmes for conservation of marine turtles were launched in various parts of the world. Rules and ordinances formulated and implemented strictly in many countries viz., Australia, USA, Durban, Surinam, State of Sabah, Oman, India etc.

Reacting to the alarming situation of their depletion from Pakistani waters, the Government of Sindh (Pakistan) declared all marine turtles as "Protected" under Sindh Wildlife Protection Ordinance (Salm, 1975) and Sindh Wildlife Protection Act 1993. Eggs of turtles are usually removed from the nests and buried at a safest place (Stancyk et al., 1980). Among others some recent studies on relocation of nests and hatching success are those of da Silva et al. (2007), Trullas and Paladino (2007), Kornaraki et al. (2006), Vanzolini (2003), to mention a few.

An intensive project on study of ecology of sea turtles of Karachi among other aspects, included establishing enclosures (hatcheries) for hatching and rearing the hatchlings for safety return to the natural environment (Firdous et al., 2009).

In the present study, egg clutches of Chelonia mydas and Lepidochelys olivacea were transplanted to

*Author for correspondence; E-mail: sohailbarkati@yahoo.com protected enclosures and the emerging hatchlings were released to the natural environment.

\section{Materials and Methods}

The present study was carried out on the sandy beaches of Sandspit (24 $\left.50^{\prime} 49^{\prime \prime N}-66^{\circ} 53^{\prime} 34^{\prime \prime} \mathrm{E}\right)$ and Hawkesbay ( $24^{\circ} 51^{\prime} 37^{\prime \prime N}-66^{\circ} 51^{\prime} 11^{\prime \prime E}$ ) along Karachi coast, Sindh, Pakistan. This is about $5 \mathrm{~km}$ long area located south west of Karachi.

Individual eggs of two species of turtles (C. mydas (green turtle) and L. olivacea (olive ridley) were collected from wild just after being laid during the period 1974 to 1997 (green turtle) and 1980 to 1997 (olive ridley); these were then relocated to protected enclosures built just above the high tidal zone at Sandspit and Hawkesbay to provide secure and safe environment.

Three enclosures measuring $80 \times 80 \mathrm{ft}$ each (6400 sq. $\mathrm{ft}$ ), one on Hawkesbay and two on Sandspit were built on high tidal zone at a distance of 50 to $3000 \mathrm{~m}$ from the nesting sites. The enclosures were made secured through a metal fence. About $1.0 \mathrm{~m} \times 1.0 \mathrm{~m}$ area was reserved for each nest. Eggs were collected and transferred within a maximum of $6 \mathrm{~h}$ of deposition with minimum disturbance to eggs. After removal, eggs were counted, placed in a bucket, carried to the enclosures (hatchery) and buried in the nest prepared for this purpose. Eggs were usually handled manually. Baldwin and Lofton (1959) also reported manual handling of eggs of loggerhead turtles at Little Cumberland Island. The hatchlings were released to the sea soon after their emergence. The nests were excavated after the 
hatching process was completed. Hatching success was calculated as the ratio of total number of hatchlings produced to the number of eggs present in the nest.

A thermistor thermometer (C-8150-60) was used to measure the temperature of the nest containing eggs. The probes of the instrument are epoxy-tipped and are equipped with 15-ft. PVC leads. A probe was placed within the centre of the clutch which was connected through a wire to a meter over the earth's surface. The nest was then filled with sand and left for incubation. The probes were waterproof and could withstand the burial in sand without affecting their sensitivity. Temperature was recorded at least twice a week till hatchlings emerged. Soon after emergence hatchlings were released to the sea.

\section{Results and Discussion}

Temperature changes. The average temperature ranged between 16.06 and $29.03^{\circ} \mathrm{C}$. Seasonal changes of temperature in different years followed almost similar pattern from 1984 to 1997 (Figs. 1 and 2). Generally June and July were the months of high temperature, whereas relatively low temperature was observed during December and February.

Nesting and hatching. Details regarding number of egg clutches (nests) transplanted, number of eggs per clutch, incubation period, number of hatchlings per clutch and hatching percentage (hatching success) of green and olive ridley during the period 1979 to 1997 is summarized in Tables 1 and 2. The values are given as total, minimum, maximum and average of respective parameters.

The incubation period of green turtles varied from 22 to 160 days whereas the yearly averages ranged between 56 and 70 days. The incubation period of olive ridley varied from 42 to 69 days, whereas the yearly averages ranged between 46 and 52 .

Transfer of nests to protected enclosures. A total of 1531980 eggs of both the species were transplanted to the enclosures, of which 1453966 (94.9\%) eggs were of green turtle and 78014 (5.09\%) eggs were of olive ridley.

Green turtles. A total of 17048 nests of green turtle were transplanted during the 19 years investigation period (1979 to 1997) with an average of 894.4 nests per year. Maximum number of nests (1549) was transplanted during the year 1985 and minimum (44) in 1979 (Table 1).
The average number of eggs per clutch per year varied from 62.2 (1994) to 104.7 (1980). More nests (8375) were available for transplantation during the first 6 years (1981-1986) compared to the last 13 years (8673) of study.

The eggs of green turtle transplanted to the enclosures ranged from 4610 in 1979 to 127337 in 1985 with an average of 76524.5 eggs per year. More eggs (117810 eggs per year) were transplanted during the first six years (1981-86) compared to the last 11 years (1987-97) of the study period (60410.7 eggs per year).

Olive ridley. Only 654 nests of olive ridley (L. olivacea) were found and transplanted over a period of 18 years (1980 to 1997) with an average of 43.6 nests per year. The number of nests fluctuated considerably from year to year varying from a minimum of $2(1996,1997)$ to a maximum of 120 (1984). The nests reduced to just few (2-8) during the last few years of the study (1993-1997).

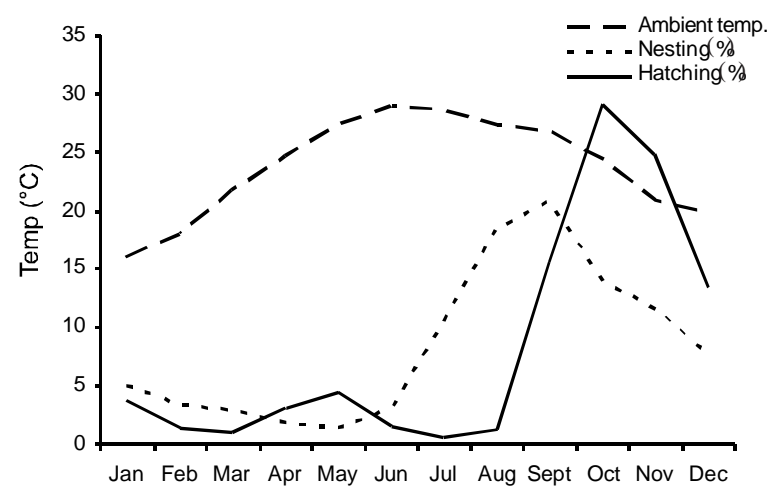

Fig. 1. Relationship between temperature changes and percent nesting and percent hatching of $C$. mydas.

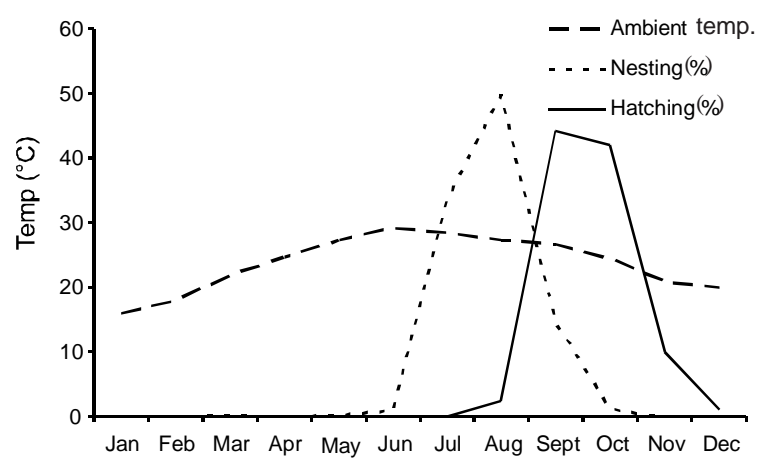

Fig. 2. Relationship between temperature changes and percent nesting and percent hatching of L. olivacea. 
Table 1. Yearly information about the number of egg clutches, eggs transplanted, incubation period, number of hatchings and percentage of hatching for green turtle (C. mydas) from Karachi Coast (Sandspit and Hawkes Bay) between 1979 and 1997, values of standard error (SE) are also given

\begin{tabular}{|c|c|c|c|c|c|c|c|c|c|c|c|c|c|c|c|}
\hline \multirow[t]{2}{*}{ Year } & \multirow{2}{*}{$\begin{array}{l}\text { No. of egg clutches } \\
\text { transplanted }\end{array}$} & \multicolumn{4}{|c|}{ No. of eggs per clutch } & \multicolumn{4}{|c|}{ Incubation period (days) } & \multicolumn{5}{|c|}{ No. of hatchlings / clutch } & \multirow{2}{*}{$\begin{array}{l}\text { Hatching } \\
(\%)\end{array}$} \\
\hline & & Min & Max. & Av. & SE & Min & Max. & Av. & SE & Total & Min & Max. & Av. & SE & \\
\hline 1979 & 44 & 81 & 135 & 104.7 & 2.44 & 40 & 86 & 62 & 9.62 & 1196 & 3 & 80 & 28.4 & 3.7 & 26 \\
\hline 1980 & 799 & 45 & 159 & 97.5 & 0.7 & 34 & 134 & 58 & 0.73 & 33907 & 1 & 125 & 60.7 & 1.02 & 43 \\
\hline 1981 & 1168 & 27 & 136 & 84.5 & 0.46 & 40 & 136 & 70 & 0.74 & 21916 & 1 & 88 & 27.0 & 0.60 & 22 \\
\hline 1982 & 1405 & 7 & 122 & 89.8 & 0.51 & 31 & 136 & 65 & 0.73 & 22587 & 1 & 109 & 23.2 & 0.57 & 18 \\
\hline 1983 & 1457 & 9 & 151 & 84.3 & 0.26 & 22 & 151 & 66 & 0.79 & 18645 & 1 & 120 & 25.4 & 0.82 & 15 \\
\hline 1984 & 1339 & 9 & 65 & 83.2 & 0.61 & 43 & 127 & 62 & 0.61 & 39994 & 1 & 132 & 36.6 & 0.77 & 36 \\
\hline 1985 & 1549 & 13 & 168 & 82.2 & 0.57 & 41 & 132 & 58 & 0.57 & 48095 & 1 & 125 & 40.5 & 0.74 & 38 \\
\hline 1986 & 1457 & 20 & 120 & 82.4 & 0.56 & 47 & 120 & 60 & 0.56 & 44037 & 1 & 135 & 40.2 & 0.77 & 37 \\
\hline 1987 & 704 & 20 & 160 & 87.6 & 0.84 & 39 & 160 & 59 & 0.84 & 13693 & 1 & 121 & 26.1 & 0.96 & 22 \\
\hline 1988 & 866 & 11 & 150 & 83.6 & 0.71 & 43 & 128 & 66 & 0.71 & 14719 & 1 & 106 & 24.1 & 0.89 & 20 \\
\hline 1889 & 717 & 28 & 121 & 88.7 & 0.71 & 43 & 121 & 64 & 0.71 & 20379 & 1 & 105 & 33.5 & 0.93 & 32 \\
\hline 1990 & 839 & 25 & 132 & 83.7 & 0.68 & 28 & 132 & 60 & 0.68 & 21297 & 1 & 117 & 32.6 & 0.90 & 30 \\
\hline 1991 & 1031 & 13 & 145 & 85.3 & 0.64 & 41 & 145 & 65 & 0.84 & 14119 & 1 & 104 & 24.3 & 0.86 & 16 \\
\hline 1992 & 785 & 7 & 163 & 85.9 & 0.71 & 44 & 132 & 64 & 0.97 & 12514 & 1 & 85 & 25.2 & 0.87 & 19 \\
\hline 1993 & 802 & 10 & 150 & 83.2 & 0.65 & 45 & 120 & 62 & 0.92 & 7385 & 1 & 83 & 16.8 & 0.76 & 11 \\
\hline 1994 & 519 & 27 & 131 & 82.2 & 0.69 & 43 & 146 & 63 & 1.15 & 6889 & 1 & 101 & 27.8 & 1.25 & 16 \\
\hline 1995 & 464 & 19 & 194 & 84.8 & 0.86 & 39 & 120 & 56 & 0.98 & 4962 & 1 & 87 & 22.9 & 1.51 & 13 \\
\hline 1996 & 475 & 32 & 181 & 84.3 & 0.92 & 36 & 122 & 61 & 0.87 & 9489 & 1 & 105 & 32.1 & 1.43 & 24 \\
\hline 1997 & 628 & 30 & 135 & 83.1 & 0.69 & 46 & 156 & 64 & 0.69 & 10895 & 1 & 104 & 28.0 & 1.05 & 21 \\
\hline
\end{tabular}

Table 2. Yearly information about the number of egg clutches, eggs transplanted, incubation period, number of hatchlings and hatching percentage for Olive Ridley (L. olivacea) from Karachi Coast (Sandspit and Hawkes Bay) between 1980 and 1997; values of standard error (SE) are also given

\begin{tabular}{|c|c|c|c|c|c|c|c|c|c|c|c|c|c|c|c|}
\hline \multirow[t]{2}{*}{ Year } & \multirow{2}{*}{$\begin{array}{l}\text { No. of egg clutches } \\
\text { transplanted }\end{array}$} & \multicolumn{4}{|c|}{ No. of eggs per clutch } & \multicolumn{4}{|c|}{ Incubation period (days) } & \multicolumn{5}{|c|}{ No. of hatchlings / clutch } & \multirow{2}{*}{$\begin{array}{l}\text { Hatching } \\
\text { (\%) }\end{array}$} \\
\hline & & Min & Max. & Av. & SE & Min & Max. & Av. & SE & Total & Min & Max. & Av. & SE & \\
\hline 1980 & 16 & 84 & 132 & 99.2 & 5.33 & 43 & 66 & 50 & 1.72 & 967 & 25 & 92 & 60.4 & 4.20 & 61 \\
\hline 1981 & 11 & 83 & 146 & 120.9 & 5.93 & 49 & 52 & 50 & 0.33 & 403 & 1 & 93 & 44.7 & 7.72 & 30 \\
\hline 1982 & 95 & 75 & 160 & 112.8 & 1.95 & 42 & 69 & 50 & 0.54 & 2386 & 2 & 116 & 27.7 & 1.98 & 22 \\
\hline 1983 & 25 & 90 & 170 & 128.6 & 3.58 & 48 & 65 & 50 & 0.35 & 472 & 5 & 98 & 33.7 & 7.01 & 15 \\
\hline 1984 & 120 & 10 & 160 & 119.1 & 2.12 & 43 & 65 & 51 & 0.32 & 5424 & 1 & 126 & 50.6 & 2.29 & 38 \\
\hline 1985 & 57 & 94 & 163 & 120.0 & 1.99 & 47 & 57 & 50 & 0.29 & 2448 & 1 & 110 & 49.9 & 4.60 & 36 \\
\hline 1986 & 61 & 78 & 164 & 121.8 & 2.45 & 46 & 56 & 51 & 0.25 & 3860 & 1 & 135 & 64.3 & 4.72 & 52 \\
\hline 1987 & 113 & 64 & 185 & 126.4 & 1.76 & 44 & 53 & 48 & 0.18 & 2799 & 1 & 101 & 25.6 & 2.11 & 20 \\
\hline 1988 & 31 & 86 & 186 & 122.4 & 3.70 & 46 & 50 & 48 & 0.23 & 230 & 1 & 40 & 11.5 & 2.63 & 6 \\
\hline 1889 & 43 & 50 & 150 & 115.5 & 3.48 & 45 & 54 & 48 & 0.36 & 1175 & 2 & 105 & 29.3 & 3.84 & 24 \\
\hline 1990 & 29 & 50 & 146 & 112.2 & 4.46 & 46 & 56 & 49 & 0.39 & 963 & 2 & 70 & 37.0 & 3.57 & 30 \\
\hline 1991 & 13 & 45 & 136 & 107.5 & 6.62 & 47 & 68 & 52 & 1.95 & 304 & 2 & 60 & 30.4 & 6.86 & 22 \\
\hline 1992 & 20 & 85 & 155 & 121.2 & 3.82 & 46 & 54 & 47 & 0.30 & 670 & 1 & 78 & 39.4 & 5.56 & 28 \\
\hline 1993 & 4 & 105 & 126 & 118.5 & 4.62 & 45 & 48 & 46 & 0.88 & 54 & 2 & 45 & 18.0 & 13.57 & 11 \\
\hline 1994 & 4 & 75 & 122 & 118.2 & 8.74 & 48 & 51 & 49 & 0.75 & 97 & 11 & 54 & 24.2 & 10.11 & 21 \\
\hline 1995 & 8 & 107 & 152 & 126.7 & 4.97 & 45 & 55 & 50 & 2.05 & 76 & 5 & 58 & 19.0 & 13.0 & 7 \\
\hline 1996 & 2 & 94 & 140 & 117.0 & & 47 & 51 & 49 & 2.00 & 173 & 81 & 92 & 86.5 & 5.50 & 74 \\
\hline 1997 & 2 & 127 & 135 & 131.0 & 4.00 & - & - & - & - & - & - & - & - & - & - \\
\hline
\end{tabular}


The eggs of olive ridley transplanted to the enclosures ranged from 234 in 1996 to 14299 in 1984 with an average of 43341 eggs per year. Period between 1982 and 1987 may be regarded as years of maximum number of eggs transplantation. A decline in number of eggs in the last five years is due to a simultaneous decline in the number of nests of olive ridley.

Release of hatchlings. A total of 391556 hatchlings (green and olive ridley combined) emerged from the eggs with an average of 20608.2 hatchlings per year, the number varying from 922 (in 1979) to 49436 (in 1986). Maximum hatchlings were produced during the period 1984-1986. The share of olive ridley was 5.39\% compared to $94.6 \%$ of green turtle hatchlings. Details of hatchings and related aspects are given by Firdous et al. (2009).

Green turtle. A total of 370414 hatchlings $(\times 19495.5$ per year) were produced during the study period (19791997) varying from 1196 (in 1979) to 48095 (in 1985). The number of hatching egg clutches hatched varied from 47 (in 1995) to 85\% (in 1989).

The number of hatchlings produced per year varied from 1 to 135 . The yearly averages ranged between 16.8 and 60.7 . The annual hatching success varied from $11 \%$ (1993) to 43\% (1980). Maximum hatchlings were produced between 1980 and 1986. It dropped down to below 10,000 (7563 per year) between 1993 and 1996 before rising again to 11077 in 1997.

Olive ridley. A total of 21142 olive ridley hatchlings (1174.5 per year) were produced during the period 1980 - 1997 varying from 11 (1994) to 4766 (1984). The egg clutches hatched varied from 50 (1995) to 100\% (1980, 1994 and 1996). The total number of olive ridley hatchlings produced per year ranged between 54 (1993) and 5424 (1984). The number of hatchlings produced per year varied from 1 to 135 . The period between 1982 and 1987 (excluding 1983) may be recognized as years of high production, whereas hatchlings were produced in significantly low number (11- 54) during 1993 - 1995. No hatchling was produced in 1997 although 262 eggs were transplanted to the enclosures (Table 2).

Nesting and hatching of green and olive ridley turtles were at their peak in August - October, when temperature started decreasing from its maximum in June-July (Figs. 1-2). The nesting generally started in the post monsoon season (August- onwards) which coincided with decreasing temperature after reaching to its peak in June-July. Moderate temperatures were favourable for nesting and hatching.

In case of green turtles nesting and hatching was very low during the colder months (December to March) and at minimum or negligible during the warmest part of the year (April to July). On the contrary, in case of olive ridley, nesting and hatching mainly occurred in July to October period and was totally absent in the months of low temperature (November to April).

The hatching rates of green turtle reported from various places are: 58 and $61 \%$ at Florida (Witham and Futch, 1977), 60\% natural hatching rate (Hirth and Carr, 1970), 50.7\% in 1959 and 50.8\% during 1960 in Costa Rica and 54.4\% from Ascension Island (Carr and Hirth, 1962), 67\% in hatchery (Bustard and Greenham, 1968), 33.9\% and 21.4 at Nancite in 1983 and 1982, respectively. Low hatching rates were assigned to monsoon (Hendrickson, 1958) and prolonged wet weather (Bustard, 1972).

In case of olive ridley hatching rate of 90-94\% was reported from two transplanted nests in Sri Lanka (Zwinenberg, 1976; AGRW, 1968). Pritchard (1969) observed a higher hatching rate (98-100\%) from the same area. da Silva et al. (2007) reported almost same average in situ hatching success (80.0\%) compared to relocated nests (78.7\%) of olive ridley in Brazil. Similarly, Kornaraki et al. (2006) did not find any significant difference in hatching success rates between hatchery and natural nesting.

In the present study, the hatching rate of green (25\%) and olive ridley (27\%) turtles are low as compared to the rates reported in the literature from other parts of the world. Minimum rate of hatching during the months of June and July may be correlated to monsoon season and prolonged wet weather as also described by Hendrickson (1958) and Bustard (1972). Hatching rates in terms of number of clutches hatched during the present study period varied from $47-85 \%$ and 50 $100 \%$ for green and olive ridley turtles, respectively (Tables 1 and 2).

The only published reference on hatching intensity of turtles from Karachi coast is that of Minton (1966) who worked on herpetology of West Pakistan during the period 1958 to 1966 . He mentioned without quantifying the rates that maximum hatching in green turtle and olive ridley at Hawkesbay occurred during late September and early October. This is in consistence with the present results. 


\section{References}

AGRW 1968. Olive-backed loggerhead turtles. Loris, 11: 203-204.

Baldwin, W.P., Lofton, J.P. 1959. The loggerhead turtles of Cape Romain, South Carolina. Abridged and annotated by D. K. Caldwell. Bulletin of Florida State Museum, 4: 309-348.

Bustard, H.R. 1972. Sea Turtles: Their Natural History and Conservation, 220 pp., Collins, London, UK.

Bustard, H.R., Greenham, P. 1968. Physical and chemical factors affecting hatching in the green sea turtle (Chelonia mydas L). Ecology, 49: 269-276.

Carr, A.F., Hirth, H. 1962. The ecology and migration of sea turtles. 5. Comparative features of isolated green turtle colonies. American Museum Novitates, 2091: 1-42.

da Silva, A.C.C.D., de Castillos, J.C., Lopez, G.G., Barata, P.C.R. 2007. Nesting biology and conservation of the olive ridley sea turtle (Lepidochelys olivacea) in Brazil, 1991/1992 to 2002/2003. Journal of Marine Biological Association of the United Kingdom, 87: 1047-1056.

Firdous, F., Barkati, S., Rahman, S. 2009. Hatching and rearing of two species of marine turtles from Karachi, Pakistan. Records of Zoological Survey of Pakistan, 19: 1-7.

Groombridge, B. 1982. The IUCN Amphibia-Reptilia Red Data Book, Part I: Testudines, Crocodylia, Rhynchocephalia, 426 pp., IUCN, Conservation Monitoring Centre, Gland, Switzerland.

Hendrickson, J.R. 1958. The green sea turtle Chelonia mydas (Linn.), in Malaya and Sarawak. Proceedings of Zoological Society of London, 130: 455535.

Hirth, H., Carr, A. 1970. The green turtle in the Gulf of Aden and the Seychelles Islands.Verhandelingen der Koninklijke Nederlandes Akademie Van Wetnshchappen Afdeling Naturkunde Tweede Reeks -Deel, 58: 1-44.
Kornaraki, E., Matossian, D.A., Mazaris, A.D., Matsinos, Y.G., Margaritoulis, D. 2006. Effectiveness of different conservation measures for loggerhead sea turtle (Caretta caretta) nests at Zakynthos Island, Greece. Biological Conservation, 130: 324-330.

Minton, S.A. 1966. A contribution to the Herpetology of West Pakistan. Bulletin of American Museum of Natural History, 134: 29-184.

Pritchard, P.C.H. 1969. Studies of the Systematics and Reproductive Cycles of the Genus Lepidochelys, Ph.D. Dissertation, University of Florida, USA.

Salm, R. V. 1975. Summary report on existing and potential marine parks and reserves around Sri Lanka, Southeast and Western India and Pakistan. In: Regional Meeting on Marine Parks and Reserves, Tehran, Iran, 6-10 March 1975, IUCN, Morges, Switzerland.

Stancyk, S. E., Talbert, O. R., Dean, J. M. 1980. Nesting activity of loggerhead turtle (Caretta caretta) in South Carolina, II. Protection of nests from raccoon predation by transplantation. Biological Conservation, 18: 289-98.

Trullas, S.C., Paladino, F.V. 2007. Microenvironment of olive ridley turtle nests deposited during an aggregated nesting event. Journal of Zoology, 272: 367-376.

Vanzolini, P.E. 2003. On clutch size and hatching success of the South American turtles Podocnemis expansa (Schweigger, 1812) and P. unifilis Troschel, 1848 (Testudines, Podocnemididae). Anais da Acadmic Brasileira de Ciencias, 75: 415-430.

Witham, R., Futch, C.R. 1977. Early growth and oceanic survival of pen-reared sea turtles. Herpetologica 33: 404-409.

Zwinenberg, A.J. 1976. The Olive ridley, Lepidochelys olivacea (Eschscholtz, 1829), probably the most numerous marine turtle today. Bulletin of the Maryland Herpetological Society, 12: 75-95. 